\title{
perifèria
}

Número 14, junio 2011

www.periferia.name

\section{DESOBEDIENCIA EPISTÉMICA: contra-hegemonías de una religión antropofágica. Una mirada etnográfica ${ }^{1}$}

\author{
J. Flávio Ferreira - Universidad de Coimbra²
}

\begin{abstract}
Resumen
Este trabajo se propone reflexionar sobre la construcción del "ser" en las religiones "afro-brasileñas" en Portugal, a partir de la inversión simbólica de la subalternidad de grupos en la sociedad y/o en contextos de 'sufrimiento' individual, cuya performance es elaborada a través de las expresiones culturales/religiosas de la (re)construcción del mundo mediante las dificultades del día a día. Estas religiones poseen variadas formaciones rituales que pueden observarse en Brasil, inclusive en términos de afirmación identitaria y política de grupos que se identifican con las 'culturas' afro-referenciadas, y cuyos cultos representan personajes de la historia colonial brasileña a través de sus 'entidades espirituales'. No obstante, pretendo centrarme en las manifestaciones de este proceso: la reciente transnacionalización en Portugal de estas prácticas que, en el 'nuevo local', tienden a revelar nuevos elementos. Entre ellos, una especie de simbolismo para una 'eficacia política' manifiesta por la importante función de los espacios de culto en la formación de 'pais-de-santo' para que la religión pueda expandirse, mientras pretende «cambiar la mentalidad política y social» en países industrializados para que las relaciones globales de poder, sobre todo económicas y políticas, sean reconfiguradas.
\end{abstract}

Palabras clave: contra-hegemonía; umbanda; transnacionalización religiosa; eficacia simbólica; antropología de las religiones y de lo simbólico.

\footnotetext{
1 Me quedo muy agradecido a Paola Santucci, socióloga de la Universidad Nacional de La Plata (UNLP/Argentina), por ayudarme con la traducción de este artículo del portugués. Agradezco a Marta Sofia Bizarro, traductora vinculada a la Facultad de Letras de la Universidad de Coimbra, Portugal, por el trabajo de revisión.

2 Doctorando en "Poscolonialismos y ciudadanía global". Centro de Estudios Sociales/Universidad de Coimbra, Portugal. E-mail: j.flavio.ferrer@gmail.com
} 


\title{
perifèria
}

Número 14, junio 2011

www.periferia.name

\begin{abstract}
This study focuses on the construction of the 'self' into the 'afro-Brazilian' religions in Portugal from the role of symbolic inversion of the subaltern groups in society and/or in contexts of individual suffering in general, whose performance is developed through cultural expressions of the (re)construction of the world through the difficulties of everyday life. These religions have different formations observable in their rituals in Brazil, including in terms of identity end political assertion of social groups that recognized themselves in 'afro-referenced cultures'. These cults represent, for example, characters of the Brazilian colonial history through its 'spiritual entities'. However, I intend to focus on the manifestations of this process that seems to be the 'new establishment' of the transnationalization of these practices in Portugal, that into the 'new local' tend to reveal new elements. Among them a kind of symbolism for a 'political effectiveness' manifest thought the significance of the formation of 'pais-de-santo' (spiritual leaders) in search of expanding their ritual places of cult. Their purpose in the 'new local' of cult is to "change the mentality" and the social policy in "industrialized countries" viewing the construction of a new paradigm - especially social and political - in the relationship between countries of the North over countries of the South.
\end{abstract}

Keywords: counter-hegemony; umbanda; religious transnationalization; symbolic efficacy; anthropology of religion.

\section{Introducción ${ }^{3}$}

\footnotetext{
"The life history is a product of its author's desire for a recongnition by essentially complex Other. It is not simply informative; it is evocative as well" (Crapanzano, 1985: 10).
}

Desde fines de 2007, realizo trabajo de campo en algunos terreiros [o barracões] (espacios sagrados de culto) en Portugal donde se practican las religiones afro-

3 El punto de partida para este análisis será un conjunto de situaciones que pude encontrar en frecuentes visitas a "terreiros" de umbanda en la región de la gran Lisboa y del Algarve, sur de Portugal, entre fines de 2007 y fines de 2009. Sus aspectos más característicos pueden ser sintetizados en lo que encontré en un espacio de culto específico, aquí revisitado por la reconstrucción de la historia de vida de su dirigente. 


\section{perifèria}

Número 14, junio 2011

www.periferia.name

brasileñas, sobre todo la umbanda. ${ }^{4}$ Este trabajo se inserta en una investigación más amplia sobre el pluralismo terapéutico en religiones de matriz africana en Brasil y el proceso de transnacionalización de estas religiones a Portugal.

Desde comienzos de 2010, disminuí mi frecuencia en el campo para volver a consultar parte del referente bibliográfico, y emprendo ahora un primer balance de los datos cualitativos que recogí. Mi atención está dirigida, por ahora, a la historia de vida de algunos de los integrantes que, generosamente, me concedieron el acceso a una parte de sus memorias personales y de sus espacios de culto.

El terreno etnográfico se centra en el barracão de ogum ${ }^{5}$, espacio de culto umbandista actualmente localizado en la región del Algarve, sur de Portugal. Después del análisis de lo que me relató el pai-de-santo del barracão de ogum, con vistas a la reconstrucción de la trayectoria de su formación (el contexto específico y los caminos para alcanzar sus objetivos) prosigo a continuación a esbozar su historia de vida.

\footnotetext{
${ }^{4}$ Umbanda es una religión brasileña de matriz africana que sincretiza ciertos cultos africanos (sobre todo Bantu), algunas de las prácticas del espiritismo, de la iglesia católica, y también cultos amerindios. Su ritualística contempla el trance/posesión como medio de comunicación entre la vida material y la espiritual. En general, su mito de fundación - ampliamente reproducido en la bibliografía sobre el tema en ciencias sociales - considera la historia del médium Zélio Fernandino de Moraes, que en 1908, en la ciudad de Niterói, Rio de Janeiro, manifestó el espíritu "Caboclo das Sete Encruzilhadas". Sin embargo, Diana Brown (1985; 1985b), quien dio más proyección a la historia del médium Zélio de Moraes, decía que esta fecha no representa necesariamente a la fundación de la religión, pero fue el marco de la primera manifestación espiritual del "Caboclo Sete Encruzilhadas". Esta perspectiva es semejante a la de Barbosa (2008: 10), que defiende que a lo largo de la Guerra de la Triple Alianza (de Brasil, Argentina y Uruguay contra Paraguay), 1864-1870, la umbanda ya era conocida entre los oficiales brasileños. Para Barbosa, umbanda sería una corruptela de 'Nbandla', generada por la dificultad de se pronunciar la palabra.

5 "Barracão" es el término que comúnmente se utiliza en Portugal para los espacios de culto; "terreiros" es la designación más frecuente utilizada en Brasil. Ogum es un orixá (un dios, de origen yoruba) en la mitología de muchas de las religiones brasileñas de matriz africana. De acuerdo con la mitología, ogum (también escrito como ògún u oggún) es un herrero-guerrero, señor de la metalurgia.
} 


\section{perifèria}

Número 14, junio 2011

www.periferia.name

Elegí este barracão, entre muchos otros, por considerar que en él están presentes aspectos generales que pude encontrar con mucha frecuencia en barracões portugueses con respecto al proceso de transnacionalización de la umbanda.

Pienso que estos aspectos son importantes para que se pueda observar tanto la umbanda en Portugal, como los fenómenos que aquí pondero como "eficacia política" para la inversión de papeles subalternos en la sociedad - características fuertemente presentes en todos los barracões a los que tuve acceso. Estos aspectos serán relatados más adelante en la historia de vida de Pai Pedro, tras algunos posicionamientos teóricos.

El trabajo etnográfico reveló un creciente movimiento de terreiros de umbanda que pretenden transnacionalizar sus prácticas, originadas en Brasil, para promover una «reforma del pensamiento» - según me dijeron dirigentes y adeptos.

Los nombres de los barracões fueron modificados, tal como los nombres de los adeptos, pais y mães-de-santo que entrevisté, por varios motivos: (a) estos barracões tienen en común el objetivo de expandir sus cultos no a través de la conquista masiva de nuevos adeptos, sino a través de la formación de nuevos pais y mães-de-santo que vendrían a formar nuevos barracões y entonces a proveer, de forma más consistente, una fuerte base para esparcir sus doctrinas en múltiples puntos de Portugal y de Europa.

Otra característica interesante es que (b) tal como ocurre frecuentemente en Brasil, los umbandistas en Portugal muchas veces asumen públicamente su identidad religiosa a través del catolicismo, ya que la umbanda todavía es vista en términos "exóticos" por la sociedad portuguesa. Estos "cuidados" son muy bien mesurados por los adeptos. Muchos de los barracões a los que tuve acceso no son conocidos ni siquiera por las personas de la propia calle en la que se localizan.

La suma de estos dos puntos ( $a$ y $b$ ) me hace abdicar de usar nombres verdaderos para proteger mejor sus identidades: por un lado, para respetar la voluntad evidente de una realización de cultos reservados y, por otro, para evitar que determinados adeptos sean reconocidos como umbandistas a través de un trabajo académico. 


\section{perifèria}

Número 14, junio 2011

www.periferia.name

Hay una cuestión que está siendo tratada en los estudios afro-brasileños y que, a pesar de no ser ampliamente aceptada, sugiere problematizar la utilización de la designación "religión afro-brasileña". El prefijo "afro" es frecuentemente instrumentalizado en el medio religioso para evocar las "purezas" africanas de estas prácticas. Como resultado, hay una visible disputa entre religiones distintas con vistas a establecer una especie de "legitimación social" (Capone, 2004: 28-29 y 139-140).

Sobre el discurso de una «mayor proximidad a las matrices africanas», las religiones "afro-brasileñas" disputan entre sí un reconocimiento de mayor conservación de las culturas africanas que consiguieron sobrevivir en Brasil.

De esta forma, dentro de todas las religiones allí presentes, los "elementos africanos" denotan aquellas que mejor consiguen mantener sus esencias, mientras las prácticas de los cultos son frecuentemente negociadas con fuerzas históricas y sociales, adaptándose a los contextos donde pretendían establecerse (Goldman, 1984: 108; Capone, 2004: 18).

Con respecto a los objetivos de este trabajo, trataré estas religiones como "religiones brasileñas de matriz africana". En otros momentos haré referencia directa a la umbanda que es justamente la práctica cuyo proceso de transnacionalización a Portugal se discute parcialmente aquí - sobre todo a través de algunas estrategias de expansión y de afirmación social de sus adeptos.

El objetivo del trabajo no es el de hacer un esbozo sobre la introducción de la umbanda en Portugal, sino el de reconstruir la historia de vida de un pai-de-santo (sacerdote) y la formación de su barracão, que acaban por simbolizar muchos de los elementos recurrentes en los diferentes espacios con los que estuve en contacto. Como ejemplo, puedo destacar el sistema de explicaciones "espirituales" para los problemas sociopolíticos "globales" contemporáneos, reflejados en discusiones sobre el acceso a la salud, la necesidad de unir el sistema biomédico con la medicina espiritual, la igualdad social y de derechos, algunas cuestiones 


\section{perifèria}

Número 14, junio 2011

www.periferia.name

relacionadas con la ecología, entre otros. Este discurso se ha desarrollado en la literatura espiritualista/umbandista en los últimos años. ${ }^{6}$

Como en Brasil, la umbanda desarrollada en Portugal parece legitimarse frente a las necesidades específicas de los adeptos por la apropiación de elementos exógenos, inherentes al "nuevo" local de práctica (lo que intentaré demostrar adelante con la historia de Pai Pedro), y frente a formaciones específicas del concepto de individuo, teniendo en cuenta factores políticos, económicos e históricos locales.

Así, dentro de las prácticas que acompañé, la salud, cuestiones emocionales y el ámbito financiero constituían la mayor parte de las necesidades de los adeptos que recurrían a sus servicios.

Por mucho que la umbanda no represente un fenómeno masivo en Portugal - al menos no en los mismos términos que en Brasil - mis hipótesis eran:

I. La receptividad a la umbanda en Portugal se debe a la ampliación de las explicaciones de los problemas de la vida cotidiana, o sea, a la introducción de una perspectiva espiritualizada del sufrimiento del individuo. Es necesario añadir que su semiología espiritual amplía el concepto de salud, entendida como un estado que refleja los procesos cotidianos muchas veces ignorados por la biomedicina (relación familiar, estructuras de pensamientos, sentimientos colectivos y personales).

II. El proceso de transnacionalización de la umbanda implica también una elaboración discursiva de sus propósitos "globales" - lo que intentaré transmitir transversalmente en este trabajo.

De hecho, el ejemplo de la salud es perfecto para tejer estas dos hipótesis. El discurso global de la umbanda se centra en cuestiones ampliamente discutidas en las ciencias sociales, como cuestiones de identidad, de género, de valores de

\footnotetext{
${ }^{6}$ En la literatura espiritualista/umbandista específicamente, aunque el debate político sea indirecto en los términos que propongo aquí, creo que un autor destacado en los últimos 10 años es Pinheiro (2003; 2006). Para la influencia de grupos umbandistas y dinámicas locales en la política pública, ver: Leistner (2009); con respecto a la politización de grupos umbandistas y de otras religiones de matriz africana en la ciudad de Rio de Janeiro, ver Giacomini (2010).
} 


\section{perifèria}

Número 14, junio 2011

www.periferia.name

igualdad; o sea, en este sentido, se puede decir que se trata de una religión para la vida. La harmonía se debe a una hermenéutica de los individuos que los reposiciona en una perspectiva sociopolítica más amplia a través del lenguaje "espiritual". Se trata de una perspectiva espiritualizada de los problemas sociales y de la ética que los atraviesa frente a un sistema (macro) económico que genera desigualdades.

Al mismo tiempo, no restan dudas de que la esfera individual, muchas veces complicada por estos procesos sistemáticos, se considera en el medio litúrgico según la moral umbandista. Así, aunque el sufrimiento de un individuo sea causado por cuestiones muy particulares, el discurso religioso va a direccionarlo y a interpretarlo de forma colectiva.

Con respecto a la salud, la umbanda no viene a proponer un sistema exclusivo de tratamiento, sino una conjugación de la práctica biomédica con una asistencia espiritual - que todavía utiliza conocimientos de farmacopea - que puede ser útil a las personas que no están en conformidad moral con la donación del cuerpo a la biomedicina.

Si entre las causas de las enfermedades están cuestiones espirituales o de conducta, el lenguaje mágico opera como un mecanismo simbólico para (re)conectar el humano a una verdad más amplia, para volverlo consciente de la unidad de su cuerpo, mente y espíritu.

Se puede conjeturar, pues, que la estrategia umbandista para establecer la harmonía de un individuo - o la misma harmonía social - se basa en una "desobediencia" en términos epistemológicos: la alianza entre diferentes saberes y formas de entender el mundo que rompe con el existencialismo de la biomedicina. Esta perspectiva ya desmonta la universalidad de la metafísica occidental, que desde el iluminismo tiende a separar la vida social e intelectual de la naturaleza y de lo inmaterial (Lock y Nguyen, 2010: 57-61).

Este fenómeno terapéutico viene a cuestionar indirectamente si el cuerpo biológico es simplemente el objeto universal comprehendido en términos de la investigación científica. Además, viene a reclamar otras fronteras posibles para el concepto 


\section{perifèria}

Número 14, junio 2011

www.periferia.name

ontológico de la salud y la enfermedad. ${ }^{7}$

A través de la historia de vida aquí presentada, emerge aún una especie de "conciencia política", con diferentes temporalidades, sobre las relaciones de poder entre las naciones que ejercen vectores de fuerzas sobre sus países periféricos.

O sea, la umbanda desarrollada en Portugal, según mis informantes y mi trabajo etnográfico hasta el momento, presenta una tendencia a revalorizar al individuo y las problemáticas que componen su "experiencia de aflicción", según una visión crítica de los vectores de fuerzas políticas y económicas en una escala global.

En términos personales, este proceso considera la necesidad de valorizar lo humano a través de la complementación de los valores que constituyen el sistema epistemológico "occidental", con la incorporación de otros valores constitutivos - a los cuales podríamos Ilamar aquí "epistemologías del sur" (Boaventura et al, 2004; Boaventura, 2007: 84-86).

Mediante especificidades epistemológicas, la simbología umbandista viene a demostrar "otras posibilidades" de racionalidad y de valores éticos en las sociedades, y acaba por presentar una propuesta de "proyecto alternativo" a las estructuras que generan exclusión y desigualdades sociales sedimentadas en el histórico proyecto imperial del Norte sobre el Sur. En otras palabras: la necesidad de cambiar el mundo desde el interior de las fuerzas que lo controlan.

\footnotetext{
7 Parto del principio de que la umbanda construye, en Brasil, un espacio de empowerment de parcelas de la población que son privadas, en mayor o menor medida, de servicios y estatutos sociales importantes: acceso a la salud, trabajo, poder de compra y de consumo, soporte jurídico, apoyo familiar. Luego, la "ritualística" de los cultos representa un local simbólico de voz para aquellos que se encuentran en posiciones subalternas en la sociedad.

Además de estas personas, hay todavía muchas otras que no son necesariamente privadas de estos servicios y estatutos, pero que presentan una disconformidad con las éticas que les son inherentes. Éste es el modelo que se aproxima más al contexto portugués. Creo que en Portugal, con respeto a la salud, la umbanda tiene fuerte apego entre las personas que no lograron buenos resultados en tratamientos en hospitales. Esta es una perspectiva preliminar. Serían necesarios más estudios en esta área.
} 


\section{perifèria}

Número 14, junio 2011

www.periferia.name

\section{Algunas justificaciones del análisis: de un punto etnográfico al análisis del todo}

El hecho de recurrir a historias de vida en este trabajo tiene que ver con la necesidad de repensar el papel de la etnografía en la reconstrucción del Otro.

En 1997, Otávio Velho reflexionó, en Globalização: antropologia e religião, sobre la resistencia general entre los antropólogos al análisis de la globalización «como evento histórico, susceptible de ser tratado como objeto de investigación» (Velho, 1997: 133$)^{8}$. Para el autor, se trata de una marca del «romanticismo» que este área del conocimiento habrá resguardado en sus perspectivas - aunque destacándose en sus cualidades empíricas - frente al otro polo ilustrativo: el iluminismo, cuyo contenido ideológico se habrá enraizado en las otras ciencias sociales.

Este "problema situacional" es discutido desde que la antropología sufre románticamente - para utilizar una de las palabras de Velho - un nuevo encuadre de sus actividades, sus metodologías y de las cuestiones que pretende analizar. ${ }^{9}$

Las propias transformaciones sociopolíticas en las sociedades pos-industriales implican un cambio en el lenguaje utilizado para analizar los procesos de globalización y de transnacionalización de determinadas prácticas, principalmente al tener en cuenta que gran parte de la producción etnográfica tiende a recaer en las formas de concepción de la "identidad" (o pérdida de identidad) relativamente a la tradición de la disciplina. ${ }^{10}$

La mezcla inevitable de categorías de análisis con discusiones acerca de las metodologías dentro de las ciencias sociales (y también de éstas con otras áreas)

\footnotetext{
8 Traducción libre.

9 Esta perspectiva es, por ejemplo, una de las bases del ampliamente conocido "debate de la racionalidad" entre Sahlins (1990) y Obeyesekere (1997), acerca de la representación antropológica y la construcción del Otro a lo largo del trabajo etnográfico.

${ }^{10}$ Ibídem.
} 


\section{perifèria}

Número 14, junio 2011

www.periferia.name

se estimuló a través de la ampliación de las perspectivas de la complejidad de los fenómenos más actuales.

La combinación de estos géneros, en este contexto, resalta Geertz (1980: 166):

es más que el hecho de que (...) investigaciones filosóficas parecen críticas literarias (...), las difusiones científicas se asemejan a fragmentos de bellas letras (...), tratados teóricos expuestos como recuerdos de viaje (LéviStrauss), argumentos ideológicos presentados como investigaciones historiográficas (Edward Said), estudios epistemológicos construidos como tratados políticos (Paul Feyerabend), (...) hasta un punto en que resulta difícil ya sea rotular a los autores - ¿qué es Foucault, un historiador, un filósofo, un teorizador político?.

Geertz hace notar que este fenómeno no refleja sólo un cambio de trazados culturales para que se pueda analizar un problema, sino también el propio cambio de la forma en la que nos vemos a nosotros mismos y a los fenómenos que nos rodean. Con expresiones como estas, que marcaron las discusiones teóricas en las ciencias sociales [sensiblemente] desde la década de 1980, surgen nuevos horizontes para la emergencia de la antropología pos-moderna.

Así, ya no se esperaba encontrar en sus terrenos de análisis la «ilusión típica de los antropólogos» (Velho, 1997: 133) de las matrices de clase y de identidad cultural fijas. Tendríamos, pues, objetos de estudio insertos en un ambiente más amplio que confiere práctica y engloba relacionalmente situaciones «fluidas, plurales, descentralizadas e ingobernables». (Geertz, 1980: 167).

Lo que fue discutido como una "crisis del saber", principalmente en la crítica del pensamiento "fragmentario" del posmodernismo, en verdad puede ser ampliamente instrumentalizado como nueva fuerza motriz en las ciencias sociales, sobre todo en la antropología.

En vez de establecer una investigación que deba recoger los elementos ampliamente difusos como «ciertos» y «errados» en la construcción del saber, pueden desde entonces justificarse apreciaciones metodológicas para que cada 


\section{perifèria}

Número 14, junio 2011

www.periferia.name

fenómeno sea revisado de acuerdo con las mejores posibilidades individuales de quien lo analiza. La ruptura con categorías hermenéuticas posibilita la diversidad interpretativa de estos fenómenos y la producción de visiones más específicas desprovistas de las pretensiones de elaboración de un "todo por la parte".

Por lo que respecta al trabajo etnográfico, sobre todo a la utilización de historias de vida, pretendo reconstruir la vida cotidiana colectiva, para después manejarla de acuerdo con otros trabajos más amplios con los que pueda estar relacionada.

De todas formas, lo que Otávio Velho pretende decir es justamente que la vulnerabilidad de la antropología viene a instaurar cambios que permiten comprender la globalización. El fruto de esta dinámica permite huir de versiones «simplificadoras, unidimensionales y reduccionistas» (1997: 134) a cambio de un entrelazamiento analítico que distingue factores políticos e ideológicos en sus campos de análisis.

Esta "mirada hacia atrás" - breve revisión de discusiones sobre la aprensión del objeto en la antropología - tiene dos motivaciones básicas que constituyen la fundamentación de este trabajo:

I. Considero que, justamente por el libre encuadramiento del objeto de estudio en el área de la antropología, se crea la oportunidad de una mayor complejización de las fuerzas sociales que lo integran;

II. a través de la reconstitución de historias de vida y de movimientos presentados en el terreno etnográfico - aunque se traten de fenómenos aparentemente aislados - es posible verificar de qué forma lo global influye en lo local y de qué forma lo local se reconstituye y dialoga con lo global. Al mismo tiempo, permite que estas distinciones - cuya finalidad es racionalizar dinámicas y (re)creaciones fluidas sean meramente instrumentales.

Mi propósito es resaltar, a través del entrelazado de estos dos puntos, breves especificidades y detalles comunes a los distintos barracões en que realicé el trabajo de campo. Así, se torna posible ofrecer más elementos para el análisis de grandes procesos de (re)aprensión del individuo a través de la actuación de un saber «local», que acaba por constituir su propia explicación de los procesos 


\section{perifèria}

Número 14, junio 2011

www.periferia.name

globales y de sus contradicciones políticas y económicas.

\section{Barracão de Ogum: la llamada de un santo. ${ }^{11}$}

Pai Pedro de ogum tiene 40 años. Su espacio de culto, el barracão de ogum, está localizado en la región de Portimão, en el sur de Portugal. Mi primera visita fue en mayo de 2008, por medio de otro barracão umbandista de la región de la gran Lisboa que sabía su dirección (a pesar de que nunca habían entrado en contacto con Pai Pedro).

Fui muy bien recibido, y por coincidencia era el día de la feijoada de preto-velho ${ }^{12}$, una ceremonia conmemorativa que honra a los pretos-velhos - una de las entidades espirituales que componen las "líneas de trabajo" con los guías de la umbanda (caboclo, preto-velho, crianças, baiano, boiadeiro, cigano).

El homenaje a la entidad espiritual contaba con la misma disposición del espacio que se puede comúnmente encontrar en terreiros de umbanda en Brasil (ver figura I): un espacio cerrado, generalmente pintado de blanco, un congá13 con "rendas" (encajes) blancos, flores que varían de acuerdo con el ritual, imágenes de santos católicos que representan los orixás de acuerdo con el sincretismo entre las religiones de matriz africana y el catolicismo en Brasil, todos dispuestos en escalera. Además, una imagen central que queda encima de todas las otras: la de Jesúscristo, representando a oxalá - orixá asociado a la creación del mundo. ${ }^{14}$

\footnotetext{
${ }^{11}$ Para la reconstrucción de la historia de vida aquí presentada, me basé en entrevistas realizadas con Pai Pedro y en intercambios de correo electrónico. Pai Pedro me fue indicado por otro local de culto en la gran Lisboa. El segundo espacio es frecuentado principalmente por personas de baja renta, portugueses, algunos brasileños y algunos mozambiqueños. Casi todos viven el la periferia de Lisboa. El barracão de ogum es frecuentado por una clase media blanca portuguesa, pero presta asistencia a personas de baja renta, casi todos del sur de Portugal.

12 Plato brasileño hecho con frijoles, aquí ofrecido a las entidades espirituales denominadas por "pretovelho".

${ }^{13}$ El altar, también escrito como gongá.

14 Oxalá puede ser aún representado de dos maneras: oxalá joven, o oxaguian, y oxalá viejo, o oxalufan. Estas dos variaciones determinan características específicas de los cultos que cuentan con la participación de oxalá y, con relación a sus filhos (hijos), o individuos que se encuentran sobre su
} 


\section{perifèria}

Número 14, junio 2011

www.periferia.name

Al lado del congá, un ogã (u ogan) comandaba los ritmos del atabaque ${ }^{15}$, cuyas variaciones de la percusión, en conjunto con las letras de las diferentes músicas cantadas, controlan la "apertura" y el "cierre" de los cultos. Así se indica la "llegada" o la "partida" de entidades espirituales específicas, y se orienta a los médiums en el proceso de trance.

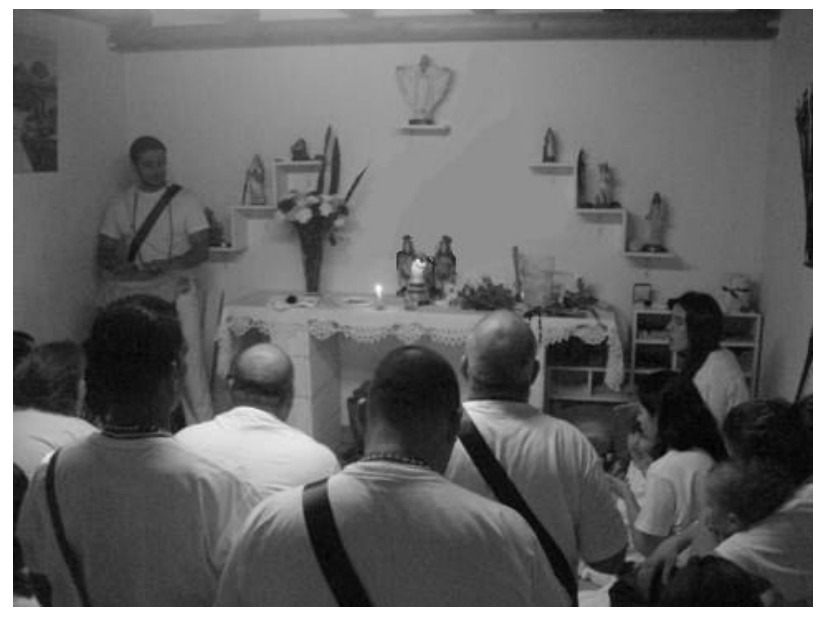

(figura I) - Foto del congá al inicio del culto.

Cerca de 20 médiums, 4 niños y algunos invitados, que estaban en la assistência ${ }^{16}$, componían el número de participantes.

El culto duró cerca de dos horas, y luego se estipuló un tiempo para las consultas, para que los invitados de la assistência, y también los adeptos, pudiesen entrar en la aruanda y hacer preguntas a los médiums que incorporaban los pretos-velhos. En general, les preguntaban sobre el origen de los males que les afligían, y luego cómo debían proceder para lograr las curas de eventuales problemas de salud, y también las resoluciones de conflictos personales, financieros y profesionales.

protección, un cambio en sus personalidades y en las tendencias a determinados comportamientos y cualidades.

${ }^{15}$ El atabaque es un instrumento musical de percusión, parecido al tambor. Es de origen africano y suele emplearse para llevar el tono y el ritmo en los rituales religiosos de matriz africana en Brasil.

16 Local exterior a la aruanda, donde se da efectivamente el culto de los adeptos por la (re)creación espacial de una ligación entre el mundo terrenal y el mundo de las entidades espirituales. 


\section{perifèria}

Número 14, junio 2011

www.periferia.name

Las consultas acaban por desempeñar una función muy similar a la del "oráculo del veneno", del clásico de Evans-Pritchard (2005) sobre los Azande, una vez que el diálogo entre el médium y el consulente (consultante) puede ser inespecífico - en el sentido en que existe una "imprevisibilidad limitada" de lo que ocurrirá. O sea, no es importante qué tipo de comunicación se establezca entre las partes, sino que esta ocurra para que, siendo positiva o negativa, tal interacción dé vida al ritual como un todo, y también a la representación específica del mundo que lo circunscribe.

Si bien la evolución de la comunicación entre un médium y un consulente es imprevisible, ésta no escapará de determinadas variantes inherentes al propio culto. Así se alimenta un ciclo completo de las vastas posibilidades comunicativas entre lo sagrado y lo humano, al mismo tiempo en que cada una de estas variantes concede un ordenamiento del espacio, de las personas, y de las manifestaciones de lo sobrenatural.

En general, la consulta puede contener orientaciones para baños con hierbas de purificación sin muchas más palabras; puede sugerir un conjunto de rezos acompañados de pequeñas ofrendas ${ }^{17}$ a las entidades que protegen un individuo; también puede detenerse en consejos de alteraciones alimentarias $y / 0$ de comportamiento; puede además ser puramente "energética" - con "limpiezas" de la energía negativa que un consultante lleva consigo y que, en parte, provocan sus problemas - prescindiendo de la utilización de palabras; o puede incluso ser negada por la propia entidad espiritual, que rehúsa a hablar con la persona, y que, en este caso, representa una comunicación a través del silencio.

De todas formas, muchas de las personas de la assistência, y todos los médiums que no participaron y que terminaron también por tomar parte en las consultas, siguieron al pie de la letra las orientaciones de los pretos-velhos, cuya característica

\footnotetext{
17 Utilización ritual, por ejemplo, de velas de colores específicos y utilización de alimentos variados: harina de mandioca, patata, maíz, cachaça [o cachaza - una bebida alcohólica muy popular en Brasil derivada del jugo de la caña de azúcar fermentado], miel, etc.
} 


\section{perifèria}

Número 14, junio 2011

www.periferia.name

más evidente es la de pasar su mensaje a través de parábolas, sin intervenciones directas ni largos discursos.

Era visible que todos estaban afectados por emociones fuertes, y la mayor parte de las personas parecían reconocer en las palabras y en las orientaciones de las entidades espirituales sus males en hechos del pasado, del presente y en las proyecciones del futuro.

Este acontecimiento tuvo dos efectos complementarios. Primero, fortaleció el sentido de "comunidad". Todos acabaron por escuchar partes de las conversaciones de otros consulentes con las entidades, silenciados por un tono más suave del ogã que seguía tocando el atabaque, mientras los otros médiums y la assistência cantaban los pontos (músicas rituales). Esto hizo que todos se solidarizasen y creasen lazos de confianza entre sí. Segundo, la demostración de confidencialidad de algunos adeptos y sus relatos de mejora de sus aflicciones a lo largo de sucesivas consultas, confirma la eficacia de los rituales.

Al mismo tiempo, la desconfianza y la incredulidad de los menos convencidos sirve de punto de partida para justificar parcialmente los orígenes de los problemas de un individuo; pues estas constituyen entonces la base de contraposición del camino que debe ser seguido: «iEs necesario tener fe para que las cosas ocurran! », me dijo uno de los participantes al ver que un consulente que estaba en la assistência se resistía a las enseñanzas del preto-velho.

Luego se formó una rueda con todos los "asistentes" sentados en el suelo y la diferencia entre estar dentro de la aruanda y estar en la assistência fue quebrada. Las entidades marcaron pontos riscados (dibujos rituales) en el suelo con la pemba ${ }^{18}$ para que energías y entidades "negativas" no invadiesen el espacio durante la ceremonia. La feijoada fue ofrecida a todos y las entidades fueron convidadas con café y cachimbos (pipa) para fumar (estas son las ofrendas preferidas de los pretos-velhos - ver figura II).

\footnotetext{
${ }^{18}$ Especie de tiza sagrada que tiene axé [energía]. Pemba designa también la Ley Mayor que rige todas las cosas. Precisamente por eso los adeptos de la umbanda son también conocidos como "hijos de pemba".
} 


\section{perifèria}

Número 14, junio 2011

www.periferia.name

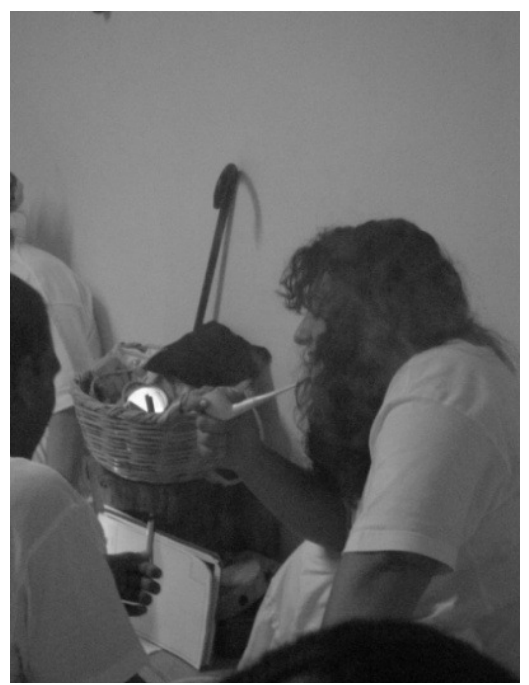

Figura II

Instrumentos rituales de los pretos-velhos siendo preparados por un assistente para el inicio de los trabalhos: cachimbo y café.

Al final, todos terminaron sus consultas y las entidades se despidieron. Ahí busqué a Pai Pedro de ogum para recoger más información. Durante el culto conversamos sobre muchas cosas, mientras yo hacía mi consulta con su preto-velho; pero Pai Pedro es un médium «medio-consciente», y no se acuerda integralmente de todo lo que ocurre cuando está en trance.

Me dijo que las entidades eligen las memorias que quedan después de los trabalhos y que, en mi caso, la conversación fue «bastante reservada». Él me invitó a un café y empezó a hablar del culto de aquel día. Le pregunté sobre la fundación del barracão y sobre cómo él se involucró con la umbanda.

Su historia no difiere de lo que se puede comúnmente encontrar en muchos espacios de culto umbandista en Brasil - principalmente al tener en cuenta, como (re)afirma Pordeus Jr. (2009), que el mayor incentivo a la conversión de nuevos adeptos a esta religión es la «aflicción», sea del ámbito emocional, de las relaciones interpersonales, o ligada a bienes materiales.

De todas formas, Pai Pedro me dijo que todo comenzó cuando era niño. Aproximadamente, cuando tenía cinco años de edad, veía ya a su madre como una persona que «vivía enferma». Él es oriundo de un pequeño pueblo localizado en la región de Mesão Frio, norte de Portugal. 


\section{perifèria}

Número 14, junio 2011

www.periferia.name

Pai Pedro me contó que su padre murió poco después de su nacimiento y que, desde entonces, los problemas de salud de su madre se agravaron. Los familiares indicaban tés y hacían rezos que Pai Pedro no entendía en aquella época, pero que dijo reconocer actualmente. Eran pequeños rituales relacionados con la brujería, el catolicismo popular, y el saber tradicional local ${ }^{19}$.

Frecuentemente iban a Vila Real, ciudad de la región con mejores recursos en relación con las consultas médicas. A veces, por falta de médicos en determinadas especialidades o de exámenes médicos más específicos, Pai Pedro dijo acordarse vagamente de haber visto a su madre irse a Oporto o a Lisboa.

Los médicos prescribían medicamentos variados, marcaban nuevos exámenes, pero ni así lograban un consenso sobre las causas de los problemas de su madre.

Pai Pedro no supo decirme cuáles eran específicamente sus problemas: era sólo un niño y los adultos no hablaban con él de lo que estaba pasando, pero me dijo que la madre «estaba muy enferma; estaba así hacía ya un tiempo», y que «nada de lo que hacían, con médicos u otras cosas la ayudaba».

Con el paso del tiempo, los persistentes problemas de salud llegaron a ser parte de su día a día. Pai Pedro recuerda que su madre muchas veces no tenía fuerzas para cuidar de él, dejándolo frecuentemente con su tía materna. Cierto día, cuando estaba a punto de completar los siete u ocho años de edad, le avisaron de que preparaban una pequeña fiesta para recibir un pariente "de fuera" de los vecinos, el hijo de un señor del poblado que se fue desde muy joven a Brasil. Este hombre, que venía a conocer a su familia y a quien sus tías y primas llamaban Augustinho, pretendía instalarse en la ciudad en el caso de que encontrase una actividad profesional. Su objetivo era conocer a sus parientes, y también aguardar la resolución de cuestiones familiares en Brasil, que implicaban un eventual retorno de su padre a Portugal para que pudiesen vivir juntos.

\footnotetext{
${ }^{19}$ Para un análisis sobre la sabiduría popular religiosa en Portugal, ver: Espírito Santo (1990); para una perspectiva sociológica de la umbanda en Portugal y sus variaciones rituales, en lo que respecta al proceso de sincretismo y al surgimiento de ritualísticas locales, ver Pordeus, Jr. (2009).
} 


\section{perifèria}

Número 14, junio 2011

www.periferia.name

Se dio inicio a la fiesta, donde estuvieron algunos invitados y curiosos del pueblo, ya que, me dijo Pai Pedro, en aquel momento «las personas de afuera siempre llamaban la atención ${ }^{20}$. Pai Pedro me contó detalles de la fiesta y destacó el momento en que su madre entró en la sala para saludar a Augustinho, quien, sin nunca haber tenido noticias de los familiares o amigos de su familia, la miró con firmeza y le dijo que sabía cuál era la causa de sus problemas.

Al principio, esta situación, por más que no hubiese llamado la atención de todos, causó cierto malestar. Actualmente, Pai Pedro se lo atribuye a dos motivos principales: la gravedad del tema, que perturbaba a su madre y a todos los familiares y amigos desde hacía algún tiempo, sin avances o perspectivas de solución; y la sorpresa de que un "forastero", familiar de sus vecinos - que no tenía noticias de los parientes o del lugar de origen de su padre - tuviese conocimiento de su estado de salud.

Al final de la fiesta, Augustinho la llamó, junto con algunas otras personas, y les contó que era un practicante de umbanda, una «religión brasileña». Le explicó a la madre de Pai Pedro de qué se trataba, y le dijo que su problema estaba en el «lugar donde ella nació». Allí, en aquel poblado, ella jamás podría descubrir que poseía una especie de mediumnidad ${ }^{21}$, y que sus males de salud se presentan como la «llamada del [su] santo», de sus guías, para el desarrollo de sus cualidades espirituales.

El uso de la "llamada" de los santos/guías como explicación para la enfermedad de los individuos es muy común en las religiones brasileñas de matriz africana. La relación entre lo humano y los orixás en el candomblé, por ejemplo, análoga a las perspectivas comúnmente encontradas en la umbanda, pretende establecer una

\footnotetext{
${ }^{20}$ De hecho, de acuerdo con las fechas que me fueron dadas a lo largo de la entrevista, identifiqué que conversábamos de acontecimientos ocurridos a mediados de 1971/73, en un poblado del norte de Portugal. Cualquier extranjero que viniese a instalarse en el poblado en aquel momento debería llamar mucho la atención. En este período Portugal era caracterizado por ser un país de emigrantes. La inmigración de brasileños, por ejemplo, la más representativa actualmente, ocurrió de forma relevante entre finales de la década de 1980 y principios de la década de 1990, como apunta Góis (2009).

${ }^{21}$ Es decir, que también debía hacerse médium.
} 


\section{perifèria}

Número 14, junio 2011

www.periferia.name

harmonía entre el aiê - el mundo material - y el orun - el mundo espiritual (Rabelo et al, 1998: 8). Esta harmonía es alcanzada mediante una serie de obligaciones individuales y colectivas regidas por principios éticos y de conducta. El cuerpo del individuo acaba por ser uno de los medios de anunciación del grado de agrado de las entidades espirituales, mediante sus actitudes - principalmente después de la toma de conciencia de su mediumnidad (ídem, 25).

De la misma forma que una entidad espiritual puede ofrecer tratamientos de cura y consejos para problemas personales, una eventual desarmonía entre lo humano y lo divino - sobre todo cuando un individuo transgrede su relación con orun - puede favorecer el aparecimiento de nuevas enfermedades.

En otro contexto, Meneses (2004) entrevista a Papá Zimba y Mamã Tamele, ambos médicos tradicionales mozambiqueños que trabajan con los espíritus manguni. Tanto Zimba como Tamele dicen haber contraído la «enfermedad de los espíritus». O sea, en cierto momento de sus vidas empezaron a presentar complejas sintomatologías que representaban una convocatoria del sagrado para el inicio de sus actividades como curanderos. Esas sintomatologías solamente fueron solucionadas a medida que estudiaron y empezaron a trabajar como tales.

A través de un lenguaje mágico, la umbanda y las otras religiones brasileñas de matriz africana encuadran al individuo en un contexto ampliado, donde la mejoría o retroceso de sus estados de salud y de sus enfermedades pasan muchas veces por su relación con lo "sagrado", y también por sus acciones para con los otros que están alrededor.

Por medio de una "semiología espiritual", que alberga códigos éticos en los más variados aspectos de su vida, un médium o un pai-de-santo puede indicar cuáles son las fuerzas que interfieren en el cuerpo y en el día a día de cada uno, y que acaban por constituir la base de su «aflicción» (Seligman, 2005). ${ }^{22}$

22 Es importante resaltar que justamente esta amplitud del nuevo encuadramiento del individuo, conjugado con su relación con lo sagrado, termina por oponerse a la naturaleza del sistema terapéutico 


\section{perifèria}

Número 14, junio 2011

www.periferia.name

De todas formas, Augustinho convenció a la madre de Pai Pedro para que se iniciase en yemanjá (o iemanjá, y también yemoja), orixá de origen yoruba y conocida popularmente en Brasil como "reina del mar". Pai Pedro no recuerda con certeza cuanto tiempo pasó, pero dice que «fue poco», y su madre, junto a Augustinho, pasó a realizar ebós. ${ }^{23}$

Con los trabalhos, su estado de salud mejoró progresivamente, hasta que dejó de sentirse mal y su sintomatología desapareció. Desde entonces Pai Pedro fue gradualmente entrando en contacto con la umbanda. Su madre continuaba los trabalhos y, a esa altura, realizaba frecuentemente consultas en casa para algunos amigos y personas que la buscaban desde las aldeas vecinas. Casi todos la buscaban para contarle problemas de salud, o para contarle la falta de especificidad del diagnóstico clínico o la ineficacia del tratamiento ${ }^{24}$. Sin embargo, no describía a las personas que la buscaban lo que hacía. Tampoco para ella las cosas estaban claras. Pai Pedro no quiso detenerse en este punto, pero dijo que su madre era considerada una especie de bruja.

A punto de completar los 12 años, Pai Pedro empezó a tener visiones y a comunicarse con entidades espirituales. Poco tiempo después, bajo las indicaciones de uno de los guías de su madre, Pedro fue "iniciado" y le fue revelada una misión: la de «formar pais y mães-de-santo» en pequeños «terreiros», con vistas a promover «prácticas de caridad y de curación», y a ayudar, junto con otros médiums, a divulgar la umbanda por Portugal.

Después de muchos años desarrollando su mediumnidad, Pai Pedro recibió un "recado" de un caboclo, uno de los guías de su madre, y de un preto-velho, el

y del reequilibrio del individuo frente a la perspectiva causal del abordaje biomédico (ver: Taussig, 1980; Young, 1982).

23 Trabalhos y ofrendas a algunas divinidades.

${ }^{24}$ Para observaciones sobre la alteración de la inversión pública en el área de salud en Portugal, sobre todo en cuanto a los porcentajes de inversión y uniformización del sistema público y del acceso de la población a la salud en las décadas de 1960 y 1970 - a confirmar la precariedad del servicio público de salud para la mayor parte de la población nacional frente a los otros países de Europa - ver: Baganha $(\mathrm{s} / \mathrm{f})$. 


\section{perifèria}

Número 14, junio 2011

www.periferia.name

mismo que la auxiliaba en los trabalhos: él debía ser elevado a pai-de-santo ${ }^{25}$, y en un año debía salir de su poblado y mudarse a otra ciudad, en la región central del país, para montar su barracão.

Las entidades le aseguraron que iban a "protegerlo" y a «cuidar de sus caminos», y que «a través de la fe» encontraría después un empleo y un local apropiados para el culto.

Y así pasó. Pai Pedro participó en un concurso y se tornó funcionario público, después de haberse mudado. Esto le permitió garantizar cierta «falta de preocupación con relación a [su] sustento», consiguiendo así determinada comodidad para el inicio de los trabalhos.

Listo su barracão, ganó nuevos adeptos. Inicialmente contaba apenas con la ayuda de Augustinho y de algunos consulentes que habían sido anteriormente ayudados por su madre, y que se disponían a viajar en algunos fines de semana para participar en los cultos. Con respecto a algunas personas que empezaron a participar en las consultas, casi todas asistían por problemas financieros y de salud.

Pai Pedro me contó que no todos eran invitados a adherirse al barracão, y los que recibían como consejo el "desarrollo espiritual" como forma de tratamiento eran muchas veces encaminados para otros barracões o incentivados a buscar otras formas de terapia.

El motivo de esta redirección residía en la «selección energética» que las propias entidades realizaban, con el fin de permitir solamente la entrada de personas que pudieran ser futuros pais y mães-de-santo. El propósito de este movimiento sería

\footnotetext{
${ }^{25}$ La elevación de un pai-pequeno a pai-de-santo implica la apertura de su propio espacio de culto. Este es también un rito de pasaje para la posesión del grado político-jerárquico más elevado en la umbanda y en el candomblé mientras se desliga parcialmente del grupo original para seguir su propio camino espiritual, su misión. Pai-pequeno, o babakekerê en el candomblé, por ejemplo [también iyakekerê en el caso de tratarse de una mãe-pequena], es el segundo sacerdote del axé, el primero a substituir al paide-santo o a la mãe-de-santo del terreiro/barracão en la eventualidad de su ausencia. Un pai o mãe-desanto está siempre asociado a un orixá, que lo protege y acaba por condicionar el funcionamiento de su espacio de culto - funcionamientos muchas veces divergentes entre sacerdotes iniciados para diferentes orixás.
} 


\section{perifèria}

Número 14, junio 2011

www.periferia.name

proporcionar la formación de espacios de culto que contribuyesen posteriormente a la difusión de la umbanda en otros puntos de Portugal y de Europa.

Todos estos detalles sumados componen lo que Pai Pedro definió anteriormente como los «caminos [que serían] cuidados» por las entidades espirituales. Estas entidades le "propiciaron" las condiciones para los inicios de los trabalhos [empleo, despreocupación financiera, un espacio para el culto, etc.].

Escogió la ciudad donde debía mudarse y montar su barracão a través de una previsión espiritual en la que vio que la mayor parte de los futuros consulentes lo buscarían por problemas relacionados con la salud, una de las funciones esenciales de las potencialidades espirituales de Pai Pedro ${ }^{26}$. De la misma forma, estas entidades preveían justamente que, en aquel local, los nuevos iniciados en la religión tendrían las condiciones espirituales ideales para convertirse en futuros pais y mães-de-santo.

Dado el contexto, emerge entonces una religión que planea desarrollarse de forma tentacular: no a través de la incorporación masiva de nuevos adeptos, sino a través de la constitución de estructuras que puedan garantizar, cuando llegue la hora, su presencia en mayores extensiones geográficas, dado que un número elevado de potenciales pais y mães-de-santo indica también la apertura de muchos espacios de culto. Este es el movimiento que parte de Augustinho, se pasa a la madre de Pedro y, a su vez, se pasa a éste último.

El discurso de Pai Pedro no es el único que menciona tales "estrategias". En los barracões de las 7 encruzilhadas y en el comando da virgem maria, localizados

\footnotetext{
${ }^{26}$ Sin embargo, debo resaltar aquí que, de hecho, al margen de algunas personas que se encontraban enfermas y que no habían logrado pronósticos clínicos, una gran parte localizaba sus sufrimientos en el área de la psicología. Los consejos espirituales y la parte ritual se efectuaban a través de charlas. De todas formas, el paralelismo de estos ritos con el tratamiento en la biomedicina (presente en muchos de los casos de enfermedades en el terreiro) se asemeja a un contexto de pluralismo terapéutico, que todavía necesita ser más estudiado. Es cierto que el fenómeno umbanda sigue siendo limitado y no tiene un número elevado de practicantes en Portugal, pero éste número es creciente y en los próximos años el escenario general será más tangible.
} 


\section{perifèria}

Número 14, junio 2011

www.periferia.name

respectivamente en la zona de Sintra y en la zona de Portimão, sur de Portugal, me fueron relatadas historias muy similares a las que recogí en el barracão de ogum.

Del barracão 7 encruzilhadas se formó un espacio de culto en la región periférica de Londres. Este acabó por tener una formación extremamente parecida al barracão de ogum, sobre todo en cuanto a las cuestiones laborales del nuevo pai-de-santo y también a las condiciones del día a día y del espacio de culto. En mi última visita al espacio de culto de las 7 encruzilhadas, se discutía la posibilidad de formar un barracão más en Ámsterdam, que posteriormente se encargaría de apoyar la formación de otro barracão en Berlín.

En el comando da virgem maria, las actividades fueron cerradas dos veces por fuertes divergencias internas sobre la elección del próximo local de apertura de un espacio de culto. Algunas disputas jerárquicas por poder y fuertes críticas directas entre los adeptos - con relación a la conducta religiosa de cada uno - terminaron por ser proyectadas en las discusiones sobre quiénes ocuparían determinados puestos rituales con la salida de algunos integrantes.

Este fenómeno es popularmente conocido entre los practicantes umbandistas y candomblés como «fuxico-de-santo» [rumores y chismorreos] (ver: Maggie, 2001). De todas formas, desde entonces, empezaron a discutirse los locales para la apertura de los nuevos barracões, para los cuales dos nuevos pais-de-santo estaban siendo preparados, inclusive con la promoción de intercambios de experiencias entre estos y diversos terreiros en Brasil.

Se formó un equipo que viajó durante dos meses por ciudades del nordeste brasileño para establecer contacto con terreiros y formalizar la invitación a los paisde-santo brasileños para visitar y apoyar los barracões portugueses. Justamente por la serie de intercambios que los barracões portugueses estaban interesados en promover con los espacios de culto en Brasil, se creó, en 2008, la REUCA ${ }^{27}$ y, anteriormente, la $\mathrm{FEUCA}^{28}$, en un intento de establecer comunicación entre los

\footnotetext{
${ }^{27}$ Red Europea de Umbanda y Cultos Afro.

${ }^{28}$ Federación Europea de Umbanda y Cultos Afro.
} 


\section{perifèria}

Número 14, junio 2011

www.periferia.name

adeptos y los barracões de pequeña dimensión todavía desconocidos en Portugal, Brasil y el resto de Europa.

Pai Pedro no conocía los barracões de las 7 encruzilhadas y del comando da virgem maria. Yo le conté las similitudes que encontré entre su espacio de culto y los otros que había conocido. Él me contestó que no le sorprendían ni las formaciones de los espacios de culto, ni el sistema de selección de nuevos adeptos, dado que el precepto básico es expandir la religión.

Él me dijo que eso no es una voluntad de los pais-de-santo, sino un «comando» que viene de las entidades para el «pueblo de aruanda» ${ }^{29}$. Pai Pedro terminó nuestra conversación señalando que este «comando» es una iniciativa del propio plan espiritual para que los «lugares con más recursos» y que históricamente ejercieron «poder sobre otras regiones y países», pasen a reequilibrar su «forma de vivir y crear harmonía entre los pueblos».

O sea, él habló de la posibilidad de otra concepción del mundo, partiendo de los locales que más tuvieron (y que aún tienen) influencia sobre la forma en la que nos vemos a nosotros mismos, agregándoles saberes subalternos que ellos mismos ayudaron a generar con el proceso colonial: otra economía de saberes en la relación Norte-Sur (Santos, 2004; 2007).

Según lo que pude percibir de la explicación de Pai Pedro, la umbanda puede llegar a protagonizar una "lucha": la umbanda entra en una "lucha" global por los derechos e igualdades para todos, aunque su efecto sea en el campo simbólico de la vida cotidiana.

Actualmente, el barracão de ogum cuenta con aproximadamente 30 médiums, de los cuales cerca de 20 tienen una fuerte presencia en los cultos. La mitad de ellos podrán llegar a ser los nuevos pais y mães-de-santo que el espacio de culto formará en los próximos 7 años.

29 Hay que aclarar que todos los pasos dados por los barracões y sus médiums son previamente determinados por el «plan espiritual». 


\section{perifèria}

Número 14, junio 2011

www.periferia.name

\section{Otras Consideraciones: "completitud" de la umbanda en Portugal, y algunas (in)conclusiones finales.}

De estos acontecimientos en cadena, emergen varios elementos que considero factores "contra-hegemónicos" en la expansión de la umbanda en Portugal. Son elementos constituyentes de la historia de Pai Pedro, pero que pude encontrar, de forma semejante, en muchos otros barracões a los que tuve acceso, sobre todo bajo la perspectiva de una reflexión epistemológica que promueve el diálogo entre las relaciones sociopolíticas e históricas.

Por un lado, Portugal - ex-metrópoli colonial y promotora del pensamiento occidental - $y$, por otro, conocimientos de una antigua colonia que llevan a un empowerment y a una inversión de la condición subalterna, a través de un lenguaje no-hegemónico, un lenguaje "mágico".

Se acepta comúnmente en el medio académico brasileño la idea de que las entidades de umbanda representan personajes de la historia colonial del país, y que la "identidad" de cada una está llena de significados, que ofrecen a los individuos el acceso a verdades/conceptos universales.

Así, el preto-velho representa al esclavo negro que consigue alcanzar una edad avanzada - contrariando la baja expectativa de vida de los esclavos en Brasil colonial - y reunir así una gran experiencia de vida. Él es el «patriarca de la raza, cuya sabiduría parece serle conferida por el peso de la edad: aquel que debe ser escuchado y cuyos consejos deben ser seguidos», siendo marcado por una «...tolerancia, por la rústica simplicidad y por un profundo sentimiento de caridad $\gg^{30}$. Los boiadeiros representan los trabajadores rurales; los vaqueros; los capataces; el sertanejo ${ }^{31}$ y su sabiduría, «la mezcla de "razas", un pueblo mestizado, con sus costumbres, supersticiones, creencias y fe» ${ }^{32}$.

\footnotetext{
30 Barros, 2010: 21. Traducción libre.

${ }^{31}$ Este término retrata una identidad conceptual relacionada con el período colonial brasileño y que hoy es utilizado como sinónimo de campesino.

32 Ídem, 34.
} 


\section{perifèria}

Número 14, junio 2011

www.periferia.name

Las sereias (sirenas), el misterio - diseminado a través de historias y leyendas en las regiones portuarias; los ciganos (gitanos), el pueblo que vaga sin destino, sin camino cierto; los caboclos ${ }^{33}$, que representan a los indios después de la llegada de los europeos, a la mestización, y también a algunos líderes de aquellas civilizaciones que allí estaban antes de los colonizadores; y así podría continuar enumerando representaciones de otros personajes...

Lo que quiero resaltar es que, por un lado, la simbología de la relación entre lo humano y lo sagrado - aquí reforzada por el saber inherente a las entidades espirituales, no sólo de la umbanda, sino también de muchas otras religiones de matriz africana - sirvió históricamente como estructura de resistencia identitaria y administración alternativa de problemas del día a día, que evidenciaban la relación colonial y el "proceso civilizatorio". Por otro lado, en la actualidad, esta misma simbología cruza el Atlántico para confrontar al "occidente" y decirle que tal vez los valores que componen su visión del mundo no sean suficientes para colocar al individuo en harmonía con su espacio, en cuanto a sus relaciones interpersonales, y aún más, con respecto a una posición sociopolítica igualitaria independientemente de la "cultura" de un individuo, de su origen y de tantos otros elementos que lo configuran en términos identitarios.

Pai Pedro reforzó, al compartir sus memorias, que estamos tratando con grupos que están al margen de la sociedad, sea en el lugar donde una vez fueron (re)creados santos, guías y orixás, o donde salió un sistema de pensamiento sobre la opresión que activó la propia necesidad de tales (re)creaciones.

Frente a las dificultades de acceso a la salud, por cuestiones estructurales del país o por cuestiones económicas individuales - o por las limitaciones del propio sistema biomédico y de su relación orgánica causal con los estados de salud y enfermedad ${ }^{34}$ -, un pequeño poblado en el norte de Portugal se convirtió en un escenario de aplicación de un saber, que aquí podemos calificar de "tradicional".

\footnotetext{
33 Descendiente de indígenas catequizados por los jesuitas.

${ }^{34}$ Ver entre otros: Good (1977); Taussig (1980); Young (1982); Verani e Morgado (1991).
} 


\section{perifèria}

Número 14, junio 2011

www.periferia.name

Es cierto que el caso de la madre de Pai Pedro se remonta a las décadas de 196070 , pero la continuación de este proyecto, en el sur de Portugal, le confiere alguna actualidad.

De los 20 médiums presentes en el día del culto en homenaje a los pretos-velhos, todos eran portugueses, y solamente el ogã - que trabaja en aquella región como instructor de capoeira - era brasileño. Sobre él, Pai Pedro bromea en torno a haber sido «difícil encontrar un portugués con ritmo para tocar los atabaques».

El predominio de portugueses fue un fenómeno que se destacó en todos los barracões a los que tuve acceso, lo que terminó por desvincular la umbanda de la perspectiva de una religión de pura afirmación de inmigrantes brasileños en Portugal.

Además de esto, se demuestra tanto la extraordinaria capacidad de la umbanda para desarrollarse en los más variados espacios - y la consecuente conquista de adeptos en el nuevo lugar de práctica -, como un elemento constitutivo muy relevante: la inversión de papeles subalternos en la sociedad a través del desarrollo de lenguajes, explicaciones y soluciones para los problemas personales y sociales. No obstante, no se pierde de vista una esencia general del culto que nos posibilita, por ejemplo, admitir que los ritos de los espacios de culto brasileños y portugueses son empleados de acuerdo con lo que es, de forma general, la estética umbandista.

En relación con el desarrollo y la apropiación de los elementos locales en Portugal, se puede destacar la incorporación umbandista del Dr. Sousa Martins [1843-1897] (ver figura III.), médico y profesor catedrático de la Facultad de Medicina de Lisboa que se identificó por realizar curas espirituales después de ser influenciado por la doctrina sistematizada de Allan Kardec. ${ }^{35}$

\footnotetext{
35 Allan Kardec era el seudónimo de Hippolyte Léon Denizard Rivail [1804-1869], matemático y pedagogo francés conocido en la doctrina espírita como el "padre del espiritismo". Su libro más conocido es Le Livre des Esprits, publicado por primera vez en 1857. De acuerdo con el IBGE (Instituto Brasileño de Geografía y Estadística), el número de adeptos del espiritismo rondaba los 2,3 millones en el año 2000 y representaba ya en aquella altura una de las religiones [a pesar de tratarse de una "doctrina", el IBGE la define como "religión"] que más crece en Brasil. El perfil, por así decir, de los adeptos de la
} 


\section{perifèria}

Número 14, junio 2011

www.periferia.name

Al Dr. Sousa Martins se atribuyen curas, inclusive después de su muerte, y hay una realización de cultos (pedidos de curación y agradecimientos por bendiciones), hasta el día de hoy, en el campo de los Mártires da Pátria, frente a su estatua, localizada frente a la Facultad de Medicina, en la región central de Lisboa (Bastos, $2001)^{36}$.

El culto al Dr. Sousa Martins tiene una fuerte apelación simbólica por ser practicado por personas de determinados estratos sociales en Portugal, y sobre todo porque su procedimiento se basa en las evocaciones de un historial de curaciones espirituales atribuidas a un "hombre de la medicina". Este culto es inclusive practicado a 20 metros de la entrada principal de la Facultad de Medicina de Lisboa, locus de una racionalidad que sustenta una perspectiva existencialista de los estados de salud y de enfermedad.

Casi con la intención de poner énfasis en la relación entre el plano "físico" y el plano "espiritual", los relatos de Pai Pedro, según él mismo parece hacer notar, terminan por evidenciar la necesidad de completar los conocimientos "científicos", a través de la acción de estos en conjunto con el saber "tradicional".

En ambos casos - del culto al Dr. Sousa Martins y de los barracões que comparten la "misión" del barracão de ogum - está presente el componente de la "incompletitud", de la búsqueda de algo que pueda reposicionar el saber médicocientífico y su perspectiva del cuerpo, a través de otro sistema más flexible y/o holístico: un sistema que "aminore" la "pasividad" impuesta al enfermo por el sistema biomédico.

Pai Pedro nos subrayó la necesidad de pensar sobre los límites y los condicionamientos epistemológicos a los que estamos sometidos. Este contexto puede ser observado en los barracões enfocados a las prácticas curativas, a través

doctrina espírita se destaca tanto por el número elevado del total de individuos practicantes como, según el IBGE, por representar el mayor nivel relativo de escolaridad de los adeptos frente a las otras religiones analizadas por el Instituto.

${ }^{36}$ Para más información sobre la vida y obra del Dr. Sousa Martins, ver: Pais (1994). 


\section{perifèria}

Número 14, junio 2011

www.periferia.name

de los frecuentes relatos de los adeptos y/o consulentes acerca de la ineficacia y/o imprecisión del diagnóstico clínico.

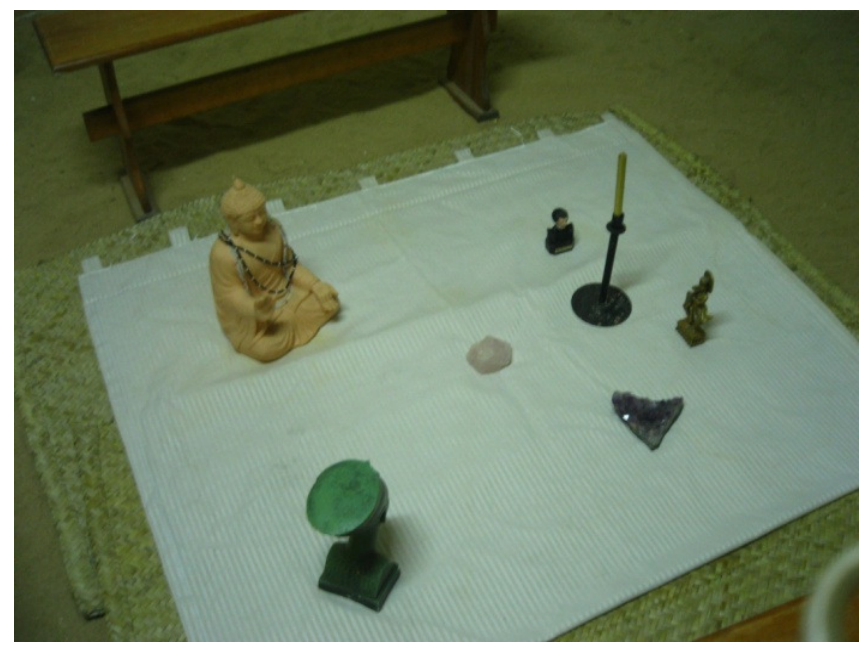

Figura III - Imagen "oriental" [arriba a la izquierda] que representa las entidades de trabalho del oriente: samuráis, chinos, mongoles, indianos, etc.; abajo, una imagen representativa de un faraón, en alusión a otras entidades que supuestamente habrán vivido en la región de Egipto; en el centro, piedras que simbolizan la utilización/manipulación de energías; arriba, a la izquierda de la vela blanca, la imagen del Dr. Sousa Martins, cuya trayectoria profesional en el área de la medicina estuvo íntimamente ligada a la doctrina espírita. El Dr. Sousa Martins fue también incorporado en la práctica de umbanda en Portugal, sobre todo en los rituales de curación.

En lo que se refiere a las prácticas curativas, de acuerdo con los relatos de Pai Pedro, la umbanda puede insertarse en una reflexión que considera las formas por las cuales la «vivencia de la enfermedad» y la «experiencia de la vivencia de la enfermedad ${ }^{37}$ son construidas y encuadradas en el campo religioso.

De la misma forma, muestra cómo los procesos de cura son absorbidos en la vida cotidiana por los nuevos adeptos. La umbanda trata lo colectivo. Busca en lo social, en lo político, en lo cultural y en lo económico elementos que luego son convertidos a la lógica ritual. Al mismo tiempo, a partir de ellos, promueve (re)significaciones

\footnotetext{
${ }^{37}$ Ver Good (1994).
} 


\section{perifèria}

Número 14, junio 2011

www.periferia.name

de las conductas interpersonales, entonces asociadas indirectamente a obligaciones rituales individuales, sistematizadas por una ligazón colectiva de lo humano con lo sagrado.

Los resultados de este proceso son evidenciados por la mejoría o retroceso del estado de salud de un individuo, mediante la satisfacción de las entidades espirituales acerca de sus conductas; este estado puede ser leído bajo la perspectiva del cuerpo como sistema bio-psico-social, lugar de expresión de los procesos de interiorización de elementos sociales, psicológicos y culturales que pasan a operar en conjunto con los procesos psico-biológicos. ${ }^{38}$

Esta trayectoria subraya la atención en la interiorización de aspectos sociopolíticos en el interior del propio culto umbandista. Es posible hacer una lectura de la umbanda como agente político-simbólico frente a las problemáticas sociales. Pero este "simbólico" se convierte en algo concreto, una vez que genera un cambio de interpretación de la realidad política. No es necesariamente una politización secundaria que se da en la difusión de la ética religiosa de los propios adeptos, proyectada en la vida cotidiana y en sus redes sociales.

El espacio ritual representa aquí la inversión simbólica de grupos excluidos de las esferas sociales, de los poderes económicos y políticos, y nos despierta para una espiritualidad [también politizada] con respecto a la aflicción individual.

En términos epistemológicos, la interiorización simbólica de las estructuras sociopolíticas en las concepciones de la salud y de la enfermedad no influencia solamente la performance ritual en la mantención de los estados del cuerpo y del espíritu. La propia idea de que la umbanda debe esparcirse de forma sólida y promover (re)equilibrios sociales en su movimiento transnacional (en ex-potencias coloniales, por ejemplo) le confiere una identidad de resistencia de acuerdo con los hechos de la actualidad. Al traer este formato, sus propuestas se insertan en los paradigmas que reconocidamente se discuten en el medio académico actualmente.

38 Para más información, ver: Good (1977; 1994); Verani e Morgado (1991); Seligman (2005) entre otros. 


\section{perifèria}

Número 14, junio 2011

www.periferia.name

Los pretos-velhos, caboclos, índios y ciganas trascienden sus papeles históricos y los procesos de embodiment de la relación de poder colonial. Así, pasan a indicar una nueva significación simbólica direccionada a sus aplicaciones rituales contemporáneas, frente a las problemáticas sociopolíticas que tienden a ser globalizadas: el acceso a la salud; la distribución de la renta y del poder económico; las relaciones sociales ligadas al género y al poder; así como muchas otras variantes que componen las diversidades identitarias y las necesidades locales y globales de mantenimiento de lo cotidiano.

\section{BIBLIOGRAFÍA}

Baganha, Maria Ioannis et al. (s/f) O Sector da Saúde em Portugal: funcionamento do sistema e caracterização sócio-profissional. Disponível em: http://www.ces.uc.pt/publicacoes/oficina/182/182.pdf

Barbosa, Wilson do Nascimento (2008) "Da 'Nbandla à Umbanda: Transformações na Cultura Afro-brasileira." Sankofa. Revista de História da África e de Estudos da Diáspora Africana, n. ${ }^{0}$ 1, junio.

Barros, Sulivan Charles (2010) "Sociabilidades Míticas na Umbanda: identidad étnica e consciência subalterna." Série Antropológica 433. Universidade de Brasília. Departamento de Antropologia.

Bastos, Cristiana (2001) "Omulu em Lisboa: Etnografias para uma Teoria da Globalização". Etnográfica, Vol. V (2), pp. 303-324.

Brown, Diana. (1985) Uma história da Umbanda no Rio. Umbanda e Política. Rio de Janeiro: Inst. de Estudos da Religião - ISER, caderno no 18, pp. 9-42. (1985b) "Mito de Origem" da Umbanda - Umbanda e Política. Rio de Janeiro: Marco Zero.

Capone, Stefania (2004) A busca da África no candomblé: tradição e poder no Brasil. Rio de Janeiro: Ed. Pallas.

Crapanzano, V. (1985) Tuhami: Portrait of a Marocain. Chicago and London: 


\section{perifèria}

Número 14, junio 2011

www.periferia.name

University of Chicago Press.

Espírito Santo, Moisés (do) (1990) A Religião Popular Portuguesa. Lisboa: Assírio \& Alvim.

Evans-Pritchard, Edward E. (2005) Bruxaria, Oráculos e Magia entre os Azande. Rio de Janeiro: Zahar.

Geertz, Clifford (1980) "Géneros confusos. La refiguración del pensamiento social." American Scholar, vol. 49, N², pp. 165-179.

Giacomini, Sonia Maria (2010) Gênero, Religião e Poder: a experiência de liderança as sacerdotisas da umbanda e do candomblé num projeto de pesquisa. Fazendo Gênero 9 - Diásporas, Diversidades, Deslocamentos. (Comunicación). En: http://www.fazendogenero.ufsc.br/9/resources/anais/1278291629_ARQUIVO_Giac omini,SoniaMariaGenero,religiaoepoder28-06-FG9-finalb.pdf

Góis, Pedro et al. (2009) "Segunda ou terceira vaga? As características da imigração brasileira recente em Portugal". Padilla, Beatriz e Xavier, Maria (coord.), Revista Migrações - Número Temático Migrações entre Portugal e América Latina, Outubro 2009, n.0 5. Lisboa: ACIDI, pp. 111-133.

Goldman, Márcio (1984) A possessão e a construção ritual da pessoa no candomblé. Dissertação de Mestrado em Antropologia Social. Rio de Janeiro: Universidade Federal do Rio de Janeiro.

Good, B. J. (1977) "The Heart of what's the matter: the semantics of illness in Iran". Cul. Med. Psychiatry 1, pp. 25-58.

(1994) Medicine, Rationality and Experience: An Anthropological Perspective. Nova Iorque: Cambridge University Press.

Kardec, Allan. [1857] (2008) O Livro dos Espíritos. São Paulo: Ed. Petit.

Leistner, Rodrigo Marques (2009) "Da discriminação social à articulação política: as religiões afrogaúchas como ação coletiva". Revista Ágora. Vitória, n¹0, pp.1-22.

Lock, Margaret y Nguyen, Vinnh-Kim (2010) Anthropology of Biomedicine. Oxford: Wiley-Blackwell. 


\section{perifèria}

Número 14, junio 2011

www.periferia.name

Maggie, Yvonne (2001) Guerra de orixá: um estudo de ritual e conflito. São Paulo: Ed. Jorge Zahar.

Meneses, Maria Paula G. (2004) "«Quando não há problemas, estamos de boa saúde, sem azar nem nada»: para uma concepção emancipatória da saúde e das medicinas." En Santos, Boaventura de Sousa e Silva, Teresa Cruz (e) (org.) Moçambique e a Reinvenção da Emancipação Social. Maputo: Ed. Centro de Formação Jurídica e Judiciária.

Obeyesekere, G. [1992] (1997) The Apotheosis of Captain Cook. Princeton: Princeton University Press.

Pais, José Machado (1994) Sousa Martins e Suas Memórias Sociais: Sociologia de Uma Crença Popular. Lisboa: Gradiva.

Pinheiro, Robson (2003) Sabedoria de Preto Velho. São Paulo: Casa Dos Espíritos. (2006) Tambores de Angola. : São Paulo: Casa Dos Espíritos.

Pordeus, Ismael Jr. (2009) Portugal em Transe - Transnacionalização das religiões afro-brasileiras: conversão e performances. Lisboa: Ed. ICS.

Rabelo, M. et al (1998) Comparando experiências de aflição e tratamento no candomblé, pentecostalismo e espiritismo. Trabalho apresentado no XXII Encontro Anual da ANPOCS, Caxambu, 27-31, Out.

Sahlins, Marshall. [1987] (1990) Ilhas de história. Rio de Janeiro: Jorge Zahar.

Santos, Boaventura de Sousa (2007) "Para Além do Pensamento Abissal: Das linhas globais a uma ecologia de saberes". Novos Estudos, no 79. CEBRAP. pp. 7194.

Santos, Boaventura de Sousa et al. (2004), "Introdução: para ampliar o cânone da ciência: a diversidade epistemológica do mundo". En Santos, Boaventura de Sousa (org.), Semear outras soluções: os caminhos da biodiversidade e dos conhecimentos rivais. Porto: Edições Afrontamento, pp. 19-101.

Seligman, Rebecca (2005) "From Affliction to Affirmation: Narrative Transformation and the Therapeutics of Candomblé Mediumship". Transcult Psychiatry, 42. 


\section{perifèria}

Número 14, junio 2011

www.periferia.name

Taussig, M. (1980) "Reification and the Consciousness of the Patient". Social Science and Medicine, 14B: 3-13.

Velho, Otávio (1997) "Globalização - Antropologia e Religião". MANA, 1997 [online] 3(1):133-154. En: http://www.scielo.br/pdf/mana/v3n1/2458.pdf

Verani, Cibele e Morgado, Anastácio (1991) "Fatores Culturais Associados à Doença da Reclusão do Alto Xingu (Brasil Central) - Considerações antropológicas sobre a abordagem epidemiológica". Cadernos de Saúde Pública, RJ, 7(4): 515-437, Out. /Dez.

Young, A. (1982) "Anthropologies of illness and sickness". Annual Review of Anthropology, vol. 11, pp. 257-85. 